\title{
Influence of sampling on magnetic susceptibility anisotropy of soft sediments: comparison between gravity and piston cores
}

Takaya Shimono $^{1 *}$, Toshitsugu Yamazaki ${ }^{1,2,3}$ and Seiko Inoue

\begin{abstract}
Anisotropy of magnetic susceptibility (AMS) has been used extensively for determining mineral orientation fabrics. One of the advantages of the AMS method for studying sediment and rock fabrics is that it is sensitive to very weak deformation. Because of its high sensitivity, however, AMS of marine sediments may easily be influenced by artificial deformation during coring and sampling. We compare magnetic susceptibility and its anisotropy between three pairs of gravity and piston cores taken at the same sites in the Okhotsk Sea. We report for the first time that artificial AMS caused by deformation is dependent on the sampling methods used. The sedimentary fabric is preserved, but declinations of the maximum axis of susceptibility $\left(K_{\max }\right)$ are inconsistent between piston and gravity cores after orientation with remanent magnetization directions. In terms of the sample coordinate, $K_{\max }$ declinations in the three gravity cores are oriented along the core-splitting surface, whereas $K_{\max }$ declinations in the three piston cores are perpendicular to the splitting surface. We attribute the artificial AMS to the stress created by the deformation of core liners when being split. When interpreting AMS data from sediment cores, it is necessary to investigate the influence of sampling using the sample coordinates. In this paper, we also report over-sampling and under-sampling of piston cores from a comparison of down-core magnetic susceptibility variations between piston and gravity cores. It is noteworthy that under-sampling as well as over-sampling can occur in the uppermost few meters of piston cores.
\end{abstract}

Keywords: Anisotropy of magnetic susceptibility; Marine sediments; Piston core; Gravity core; Artificial deformation

\section{Findings Introduction}

Anisotropy of magnetic susceptibility (AMS) has been used extensively for determining mineral orientation fabrics (e.g., Hrouda 1982; Tarling and Hrouda 1993). AMS in marine sediments has been applied to a wide variety of studies including paleocurrents in depositional processes (Liu et al. 2001; Abdeldayem et al. 2004; Parés et al. 2007) and paleostresses in accretional prisms (Housen et al. 1996; Ujiie et al. 2003; Kanamatsu et al. 2012). One of the advantages of the AMS method for studying sediment and rock fabrics is that it is sensitive to very weak deformation and that it can be measured rapidly (Tarling and Hrouda 1993).

\footnotetext{
*Correspondence: t_shimono@geol.tsukuba.ac.jp

${ }^{1}$ Graduate School of Life and Environmental Sciences, University of Tsukuba,

1-1-1 Tennodai, Tsukuba, Ibaraki 305-8572, Japan

Full list of author information is available at the end of the article
}

Because of its high sensitivity, AMS of marine sediments may easily be influenced by artificial deformation during coring and sampling. Copons et al. (1997) reported laboratory-induced magnetic fabric in lake sediment cores taken with a piston corer. They found that the maximum axis of susceptibility $\left(K_{\max }\right)$ is horizontal and parallel to the core-splitting surface and the minimum axis of susceptibility $\left(K_{\min }\right)$ is perpendicular to bedding planes. They suggested that the observed magnetic fabric was created by the compression applied on the core surface when cores were half-split and subsampled using plastic boxes. On the other hand, Gravenor et al. (1984) proposed that when pushing plastic boxes into soft sediments, $K_{\max }$ directions could be altered to be perpendicular to the core-splitting surface, which is the pushing direction. Aubourg and Oufi (1999) reported coring-induced AMS in sediment cores taken with an Ocean Drilling Program (ODP) Advanced Piston 
Corer. They found that $K_{\max }$ declinations were distributed horizontal and parallel to the core-splitting surface and that $K_{\min }$ declinations were concentrated almost perpendicular to bedding planes but showed a small tilt. They suggested that the piston coring resulted in a weak alignment of magnetic minerals in a conical fabric with the apex parallel to the vertical caused by friction with a core liner. These studies indicate that to improve the reliability of AMS for geological applications, it is necessary to better understand artificial influences at coring and sampling.

In this study, we compare magnetic susceptibility and its anisotropy between gravity and piston cores taken at the same sites. We report for the first time that artificial AMS caused by deformation of sediments is dependent on sampling methods. We also present thickening/ thinning of piston cores compared with gravity cores. Previously, comparison of different sampling methods at the same site was rarely conducted partly because of limited ship time (Yamazaki and Kanamatsu 2007).

\section{Piston and gravity coring}

When sea-bottom sampling is conducted, an appropriate corer is selected considering the purpose of the sampling. A piston corer can recover a relatively longer sequence of sediments than that collected by a gravity corer. This leads to a negative pressure produced by the piston, which makes it easier for sediments to enter tubes. However, upward acceleration of the piston disturbs the sediment texture and structure. When the motion of a piston is slower than the penetration of the corer at the beginning of the penetration, the uppermost part of the sediment column is missed and/or shorter core recovery than penetration occurs. A gravity corer can recover the uppermost sediments in principle, although it cannot take long cores because of friction.

The depth scale of marine sediments collected by coring is of key importance for the precise calculation of sedimentation rates and fluxes. However, gravity coring may result in sediment under-sampling, while imperfect piston coring (upward acceleration of a piston) may result in over-sampling. Under-sampling leads to sediment thinning and over-sampling leads to sediment thickening compared with the actual length. See Skinner and McCave (2003) and Széréméta et al. (2004) for details. It should be noted that sediment thinning and thickening are not elastic deformations (stretching and squeezing) because the magnetic susceptibility and density of sediments do not change by either over-sampling or under-sampling (Skinner and McCave 2003; Széréméta et al. 2004).

\section{Materials and sampling}

Three approximately 18-m-long piston cores (MR0604PC5, PC6, and PC7) were collected from the central part of the Okhotsk Sea (Figure 1) during the R/V Mirai MR06-04 cruise in 2006. The piston corer used had a 20 -m-long core-barrel and weighed about $1,500 \mathrm{~kg}$. The uppermost parts of the cores suffered from perturbation during coring. Except for these parts, no coring-induced disturbance could visually be recognized. To obtain undisturbed surface sediments, three gravity cores, each of which was $7 \mathrm{~m}$ long, were taken at the same positions as the three piston cores during the R/V Yokosuka YK0712 cruise in 2007. The gravity corer used was $7 \mathrm{~m}$ long and weighed $500 \mathrm{~kg}$. Pairs of gravity and piston cores, YK0712-GC1 and MR0604-PC7, YK0712-GC8 and MR0604-PC6, and YK0712-GC9 and MR0604-PC5, were taken at almost the same positions (Table 1). Water depths of the coring sites range from about 800 to $1,200 \mathrm{~m}$. The cores are composed of diatom-bearing, olive-gray, silty clay. All cores contain a few thin volcanic ash layers and some detrital components. The results of a paleomagnetic and rock magnetic study of these cores were reported in Inoue and Yamazaki (2010) and Yamazaki et al. (2013). The ages of the bottom of the gravity cores range from approximately 120 to $160 \mathrm{ka}$.

The core liners for the piston cores consist of polycarbonate tubes with a 7.4- $\mathrm{cm}$ inner diameter and were split lengthwise into two halves after core recovery. Gravity cores that do not have a piston do not require airtightness, so acrylic-resin semi-cylindrical trays with an inner width of $11 \mathrm{~cm}$ attached together with plastic tapes were used for core liners; they are easier to split than whole-round tubes. The core sediments of each $1-\mathrm{m}$ section were split into halves from the bottom to top using a fishing line. All samples for AMS measurements were taken sequentially from the center of the half-split core surface by inserting cubic plastic boxes with a volume of $7 \mathrm{~cm}^{3}$ by hand. The plastic boxes had sharp inward edges to reduce friction at insertion. The cut surfaces of the cores were lightly scraped away to allow visual core description before sampling. Some samples were taken onboard, and others were taken at sampling parties about 1 month after the cruises.

\section{Methods}

Magnetic susceptibility and its anisotropy were first measured for all samples using a KappaBridge KLY-3S susceptometer (AGICO Inc., Brno, Czech Republic) obtained from the Geological Survey of Japan (GSJ), National Institute of Advanced Science and Technology (AIST). AMS is represented by a symmetrical secondrank tensor, which is described by a triaxial ellipsoid with the principal eigenvectors, $K_{\max } \geq K_{\text {int }} \geq K_{\min }$, corresponding to the maximum, intermediate, and minimum susceptibility axes, respectively. The mean susceptibility $\left(K_{\mathrm{m}}\right)$ by volume is defined as the mean of $K_{\mathrm{max}}, K_{\mathrm{int}}$, and $K_{\mathrm{min}}$. The following parameters were used to quantify 


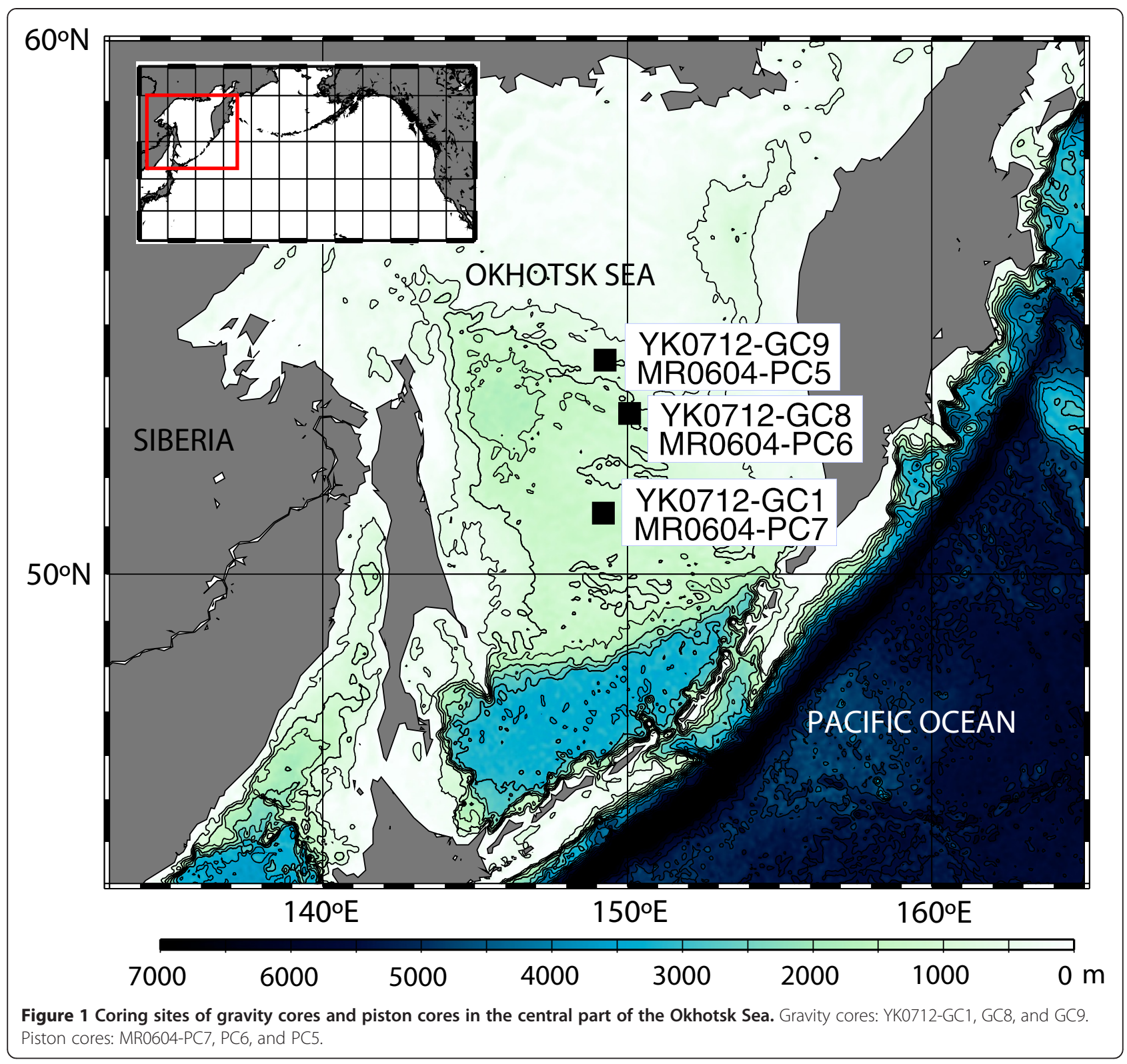

Table 1 Positions, water depths, core lengths, and coring systems of studied sites

\begin{tabular}{|c|c|c|c|c|c|}
\hline Core ID & Latitude & Longitude & Depth (m) & Core length $(\mathrm{m})$ & Corer \\
\hline \multicolumn{6}{|l|}{ South } \\
\hline YK0712-GC1 & $51^{\circ} 16.4^{\prime} \mathrm{N}$ & $149^{\circ} 12.5^{\prime} \mathrm{E}$ & 1,251 & 6.3 & Gravity \\
\hline MR0604-PC7 & $51^{\circ} 16.6^{\prime} \mathrm{N}$ & $149^{\circ} 12.6^{\prime} \mathrm{E}$ & 1,251 & 18.4 & Piston \\
\hline \multicolumn{6}{|l|}{ Central } \\
\hline YK0712-GC8 & $53^{\circ} 17.0^{\prime} \mathrm{E}$ & $150^{\circ} 04.7^{\prime} \mathrm{E}$ & 1,145 & 6.7 & Gravity \\
\hline MR0604-PC6 & $53^{\circ} 16.9^{\prime} \mathrm{E}$ & $150^{\circ} 04.7^{\prime} \mathrm{E}$ & 1,148 & 18.7 & Piston \\
\hline \multicolumn{6}{|l|}{ North } \\
\hline YK0712-GC9 & $54^{\circ} 19.0^{\prime} \mathrm{E}$ & $149^{\circ} 16.1^{\prime} \mathrm{E}$ & 828 & 6.9 & Gravity \\
\hline MR0604-PC5 & $54^{\circ} 19.0^{\prime} \mathrm{E}$ & $149^{\circ} 16.1^{\prime} \mathrm{E}$ & 831 & 17.9 & Piston \\
\hline
\end{tabular}


the shape of the magnetic ellipsoids: $P^{\prime}$ representing the anisotropy degree and $T$ representing the shape of the AMS ellipsoid calculated from the three principal axes (Jelínek 1981).

$$
\begin{aligned}
& P^{\prime}=\exp \sqrt{\left\{2\left[\left(\eta_{1}-\eta_{m}\right)^{2}+\left(\eta_{2}-\eta_{m}\right)^{2}+\left(\eta_{3}-\eta_{m}\right)^{2}\right]\right\}} \\
& T=\left[2\left(\eta_{2}-\eta_{3}\right) /\left(\eta_{1}-\eta_{3}\right)\right]-1
\end{aligned}
$$

where $\eta_{1}=\ln \left(K_{\max }\right), \eta_{2}=\ln \left(K_{\text {int }}\right), \eta_{3}=\ln \left(K_{\min }\right)$, and $\eta_{m}=$ $\left(\eta_{1}+\eta_{2}+\eta_{3}\right) / 3$. During deposition and sedimentary compaction, magnetite grains with a shape anisotropy tend to preferentially fall with their $K_{\min }$ axes perpendicular to the depositional plane (e.g., Tauxe 1998). Consequently, the magnetic fabric expresses an oblate shape $(T>0)$ when sedimentary fabric is preserved.

To orient the samples to geographic coordinates, we used paleomagnetic directions. Natural remanent magnetization (NRM) measurements with stepwise alternating field (AF) demagnetization were performed using a cryogenic magnetometer system with an in-line static AF demagnetizer (2G Enterprises model 760, Applied Physics Systems, Inc., Mountain View, CA, USA) in a magnetically shielded room of GSJ, AIST. Generally, the maximum angular deviation (Kirschvink 1980) values were less than $5^{\circ}$, which indicates that stable primary magnetization was preserved (Inoue and Yamazaki 2010; Yamazaki et al. 2013). The mean paleomagnetic inclinations of the cores are close to those expected from the geocentric axial dipole model for the respective site latitudes.

In this study, we refer to two coordinate systems: the sample coordinates that are not oriented with respect to the true north and the geographical coordinates oriented using paleomagnetic directions. For the sample coordinates, we use the right-handed sample orientation convention: $+\mathrm{X}$ points vertical upward against the split face of the working halves of the cores, $+Y$ points to the right within the core surface, and $+\mathrm{Z}$ points down-core.

\section{Results}

The variation patterns and values of the magnetic susceptibility of gravity and piston cores are very similar at each site (Figure 2). Thus, the gravity and piston cores at each site can be correlated. From the correlations shown in Figure 2, it is revealed that the uppermost parts of the piston cores were missed. Moreover, over-sampling and/or under-sampling of piston cores (Skinner and McCave 2003; Széréméta et al. 2004; Yamazaki and Kanamatsu 2007 ) is evident. Approximately $13 \%$ under-sampling occurred between 0.2 and $2.8 \mathrm{~m}$ of the piston core MR0604PC7 compared with the gravity core YK0712-GC1 between 1.0 and $4.0 \mathrm{~m}$. On the other hand, over-sampling of approximately $42 \%$ occurred between 2.8 and $5.1 \mathrm{~m}$ of the same piston core. Under-sampling and over-sampling similar to those recognized in MR0604-PC7 were observed in the other two piston cores: approximately $31 \%$ under-sampling between 0.6 and $1.7 \mathrm{~m}$ and approximately $42 \%$ over-sampling between 1.7 and $3.5 \mathrm{~m}$ in MR0604PC6, and approximately 44\% under-sampling between 0.4 and $2.2 \mathrm{~m}$ and approximately $19 \%$ over-sampling between 2.2 and $4.3 \mathrm{~m}$ in MR0604-PC5. The magnetic susceptibility values of the corresponding intervals between the piston and gravity cores are almost the same (Figure 2). This means that the under-sampling and oversampling were not caused by stretching and squeezing of the sediments, as pointed out by previous studies (Weaver and Schultheiss 1983; Skinner and McCave 2003; Széréméta et al. 2004).

We compared the AMS between the entire depth intervals of gravity cores and the corresponding upper parts of piston cores (above solid tie lines in Figure 2). $K_{\text {min }}$ inclinations are almost vertical for most parts of the gravity and piston cores (Figure 3), which indicates that the primary sedimentary fabric was preserved even in the over-sampled intervals of the piston cores. We excluded samples with $K_{\min }$ lower than $45^{\circ}$, for which the sedimentary fabric was not preserved. The excluded samples accounted for $7 \%$ to $12 \%$ of all samples. The degree of anisotropy $\left(P^{\prime}\right)$ was small in general, i.e., less than 1.08 (Figure 4). The shape parameter $T$ was larger than 0 for majority of the samples (Figure 4). These results indicate a weakly oblate shape of the AMS ellipsoid for the studied sediments. There is no significant difference in the AMS parameters $\left(T, P^{\prime}\right.$, and $K_{\min }$ inclination) between the piston and gravity cores from the same sites (Figures 3 and 4).

With regard to geographical coordinates, $K_{\max }$ declinations were not consistent between the pairs of gravity and piston cores although they were taken at the same sites (Figure 3 ). For example, $K_{\max }$ of the gravity core YK0712-GC9 was dominantly oriented to northeastsouthwest directions, whereas $K_{\max }$ of the piston core MR0604-PC5 dominantly aligned north-south. In the sample coordinates, $K_{\min }$ axes were generally vertical, and $K_{\max }$ and $K_{\text {int }}$ axes were mostly horizontal. An interesting observation was that $K_{\max }$ axes of the gravity corers (YK0712-GC1, GC8, and GC9) were dominantly distributed in the $Y$-axis direction $\left(90^{\circ}\right.$ to $\left.270^{\circ}\right)$, whereas $K_{\max }$ axes of the piston corers (MR0604-PC7, PC6, and PC5) dominantly aligned the $X$-axis $\left(0^{\circ}\right.$ to $180^{\circ}$; Figure 3$)$. These results indicate that the AMS of these cores represent artificial deformation dependent according to the sampling methods.

\section{Discussions}

Our results indicate that the magnetic fabric is a sensitive indicator of artificial deformation of soft sediments and that sampling procedures influence AMS (Figure 3). 

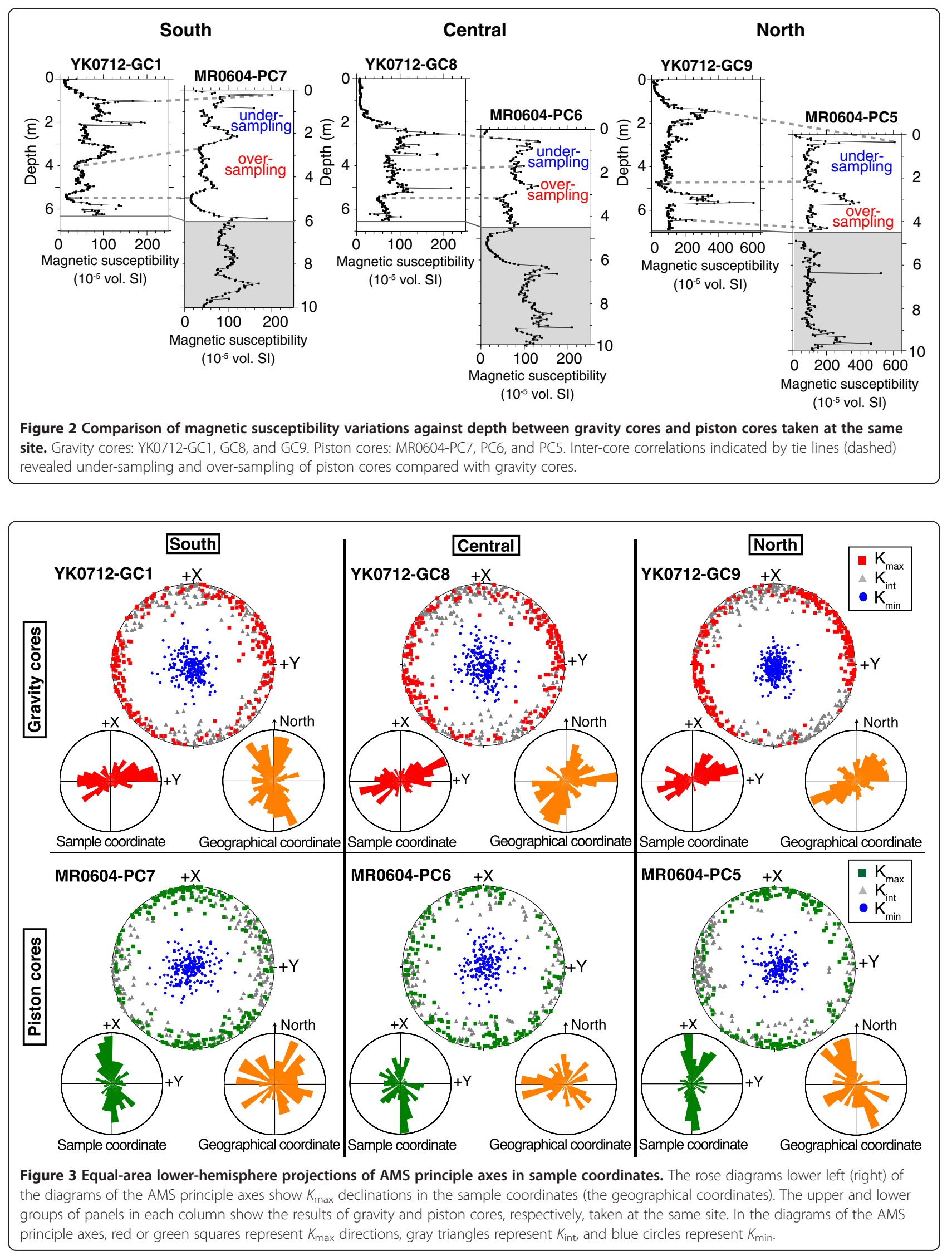


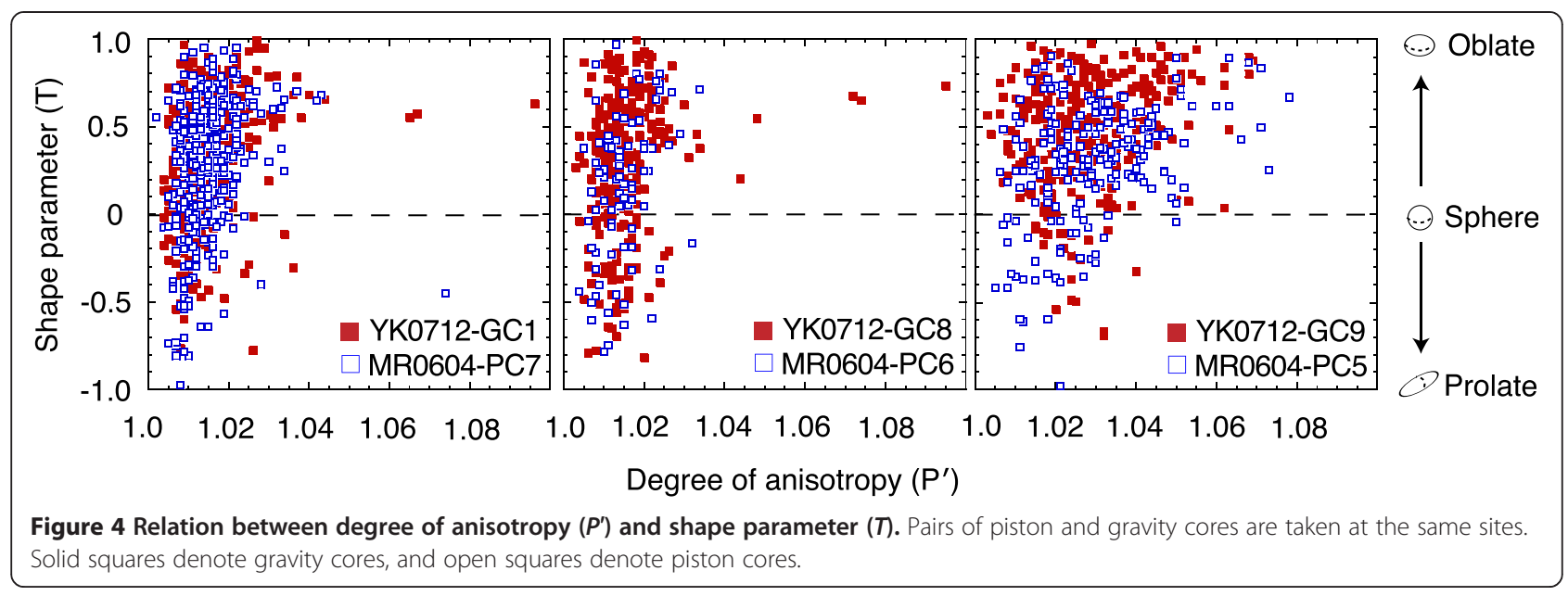

We believe that the deformation of the core liners after half-splitting can explain the artificial AMS that depends on the sampling methods (Figure 5). We found that the semi-cylindrical trays of the gravity cores sagged by the weight of sediments after being filled with sediments and split in halves. The width of the trays increased by 5 $\mathrm{mm}$ after half-splitting, which constitutes the $Y$ direction in the sample coordinates. This may have created an extensional stress on the gravity core sediments and made the alignment of $K_{\max }$ parallel to the split surface. The possible influence on the AMS by the change from a circular to a slightly oblate core section after splitting was suggested also by Copons et al. (1997) and Aubourg and Oufi (1999). On the other hand, the edge of the halfsplit core liners of the piston cores used during this cruise contracted inward and the width of the core liners decreased when being split. This was due to a release of a stress that remained in the polycarbonate tubes which was probably acquired during manufacturing processes. The inward contraction created a compressional stress on the piston core sediments and made the $K_{\max }$ alignment perpendicular to the split surface (Figure 5). The predicted fabrics of the piston cores were slightly more complex; extensional strain parallel to the $Y$-axis may have occurred near the bottom of the core liner (i.e., near the bottom of the ' $U$ ' shape in Figure $5 b$ ) as in a folded elastic layer. However, we believe that the strain would have had a negligible influence near the center of the cores where the samples were taken. In this study, the sampling procedures after core recovery were the same for both the gravity and piston cores. Thus, neither half-splitting of core sections nor insertion of plastic boxes for the AMS measurements into the split surfaces of the sediments is responsible for the difference of AMS measurements between the gravity and piston cores.

An alternative possibility for the cause of the artificial AMS is that stress due to half-splitting and scraping of the cut surface of the cores may have caused the alignment of $K_{\max }$ declination into the $Y$-axis direction (a)

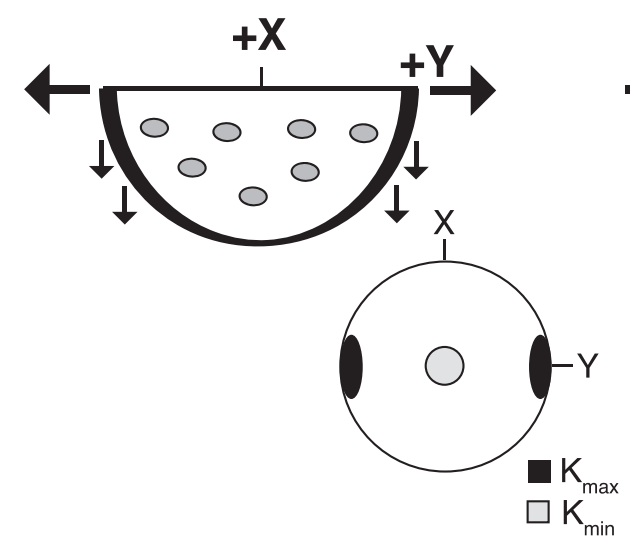

(b)

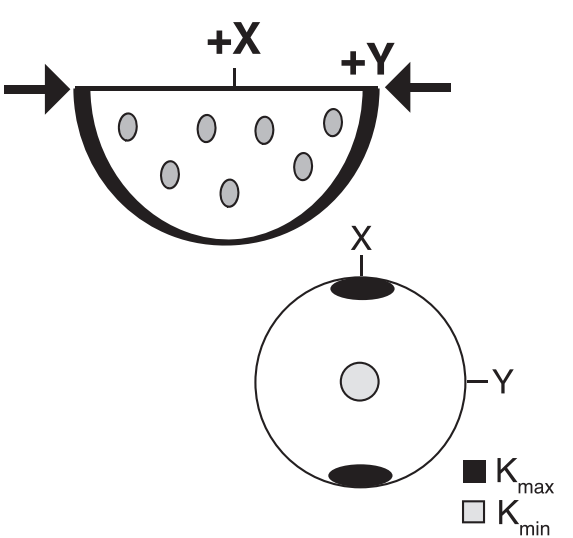

Figure 5 Sketches showing possible cause of artificial AMS observed in (a) gravity and (b) piston cores. In the sample coordinates, the $X$-axis ( $Y$-axis) is normal (parallel) to the core surface. 
(Copons et al. 1997). For the gravity cores, the influence of the core liner deformation may have been smaller at the center of the cores than that of scraping because of the larger core diameter. For the piston cores, on the other hand, the influence of the core liner deformation may be stronger than that of splitting or scraping because of the smaller core diameter, which may have resulted in the alignment of $K_{\max }$ declination to the $X$-axis direction. This explains the observation that the degree of anisotropy $\left(P^{\prime}\right)$ of piston cores is not larger than that of gravity cores.

Parés et al. (1999) classified three stages of fabric development in mud rocks using AMS: earliest deformation, pencil structure, and weak cleavage. The earliest deformation stage is characterized by the alignment of $K_{\max }$ declination to a particular direction while the sedimentary fabric is preserved. The magnitude of the extensional or compressional stresses associated with the deformation of core liners in this study may be roughly equivalent to that of stresses in the earliest deformation stage of Parés et al. (1999).

The paleomagnetic directions of our cores were not influenced by artificial AMS; the inclinations of the cores were close to those expected from the geocentric axial dipole model (Inoue and Yamazaki 2010). Rosenbaum et al. (2000) reported that artificial AMS is accompanied by distorted paleomagnetic directions, but a considerably large degree of anisotropy $\left(P^{\prime}\right)$ of their sediments indicated that the deformation was much more severe.

In conclusion, when interpreting AMS data from sediment cores, it is necessary to examine the influence of sampling using sample coordinates. AMS of sediment cores may not necessarily reflect sedimentary environments such as paleocurrent directions or tectonic stress directions. The composition and performance of core liners should be carefully examined to avoid deformation of sediments. Our comparison of down-core magnetic susceptibility variations between the piston and gravity cores revealed oversampling and under-sampling of the piston cores. It is noteworthy that under-sampling can occur in the uppermost few meters of piston cores; Skinner and McCave (2003) mentioned a possibility of only oversampling for a piston core. We believe that undersampling of our piston cores was due to delayed working of the piston at the sediment/water interface.

\section{Competing interests}

The authors declare that they have no competing interests.

\section{Authors' contributions}

TS and SI carried out the paleomagnetic and rock-magnetic measurements. All contributed to the discussion, and TS and TY wrote the manuscript. All authors read and approved the manuscript.

\section{Acknowledgements}

The cores were obtained through the cooperation of all onboard scientists, marine technicians, officers, and crew of the MR06-04 cruise of R/V Mirai and YK07-12 cruise of R/V Yokosuka. We thank Naomi Harada and Tatsuhiko Sakamoto, the chief scientists of the cruises, for arranging our participation in the project. We thank Yujiro Ogawa and Akira Takada for their encouragement. Constructive comments from two anonymous reviewers greatly helped improve the manuscript.

\section{Author details}

1 Graduate School of Life and Environmental Sciences, University of Tsukuba, 1-1-1 Tennodai, Tsukuba, Ibaraki 305-8572, Japan. ${ }^{2}$ Geological Survey of Japan, AIST, 1-1-1 Higashi, Tsukuba, Ibaraki 305-8567, Japan. ${ }^{3}$ Atmosphere and Ocean Research Institute, University of Tokyo, 5-1-5 Kashiwanoha, Kashiwa, Chiba 277-8564, Japan.

Received: 20 September 2013 Accepted: 27 December 2013 Published: 27 May 2014

\section{References}

Abdeldayem AL, Ikehara K, Yamazaki T (2004) Flow path of the 1993 HokkaidoNansei-oki earthquake seismoturbidite, southern margin of the Japan sea north basin, inferred from anisotropy of magnetic susceptibility. Geophys J Int 157:15-24, doi:10.1111/j.1365-246X.2004.02210.x

Aubourg C, Oufi O (1999) Coring-induced magnetic fabric in piston cores from the western Mediterranean. Proc ODP Sci Results 178:1-61

Copons R, Parés JM, Dinarés-Turell J, Bordonau J (1997) Sampling induced AMS in soft sediments: a case study in Holocene glaciolacustrine rhythmites from Lake Barrancs (Central Pyrenees, Spain). Phys Chem Earth 22:137-141

Gravenor CP, Symons DTA, Coyle DA (1984) Errors in the anisotropy of magnetic susceptibility and magnetic remanence of unconsolidated sediments produced by sampling methods. Geophys Res Lett 11:836-839

Housen BA, Tobin HJ, Labaume P, Leitch EC, Maltman AJ, The Ocean Drilling Program Leg 156 Shipboard Science Party (1996) Strain decoupling across the decollement of the Barbados accretionary prism. Geology 24:126-130, doi:10.1130/0091-7613(1996)024<0127:SDATDO>2.3.CO;2

Hrouda F (1982) Magnetic anisotropy of rocks and its application in geology and geophysics. Geophys Surv 5:37-82

Inoue S, Yamazaki T (2010) Geomagnetic relative paleointensity chronostratigraphy of sediment cores from the Okhotsk Sea. Palaeogeogr Palaeoclimatol Palaeoecol 291:253-266

Jelínek V (1981) Characterization of magnetic fabric of rocks. Tectonophysics 79:T63-T67

Kanamatsu T, Parés JM, Kitamura Y (2012) Pliocene shortening direction in Nankai Trough off Kumano, southwest Japan, Sites IODP C001 and C002, Expedition 315: anisotropy of magnetic susceptibility analysis for paleostress. Geochem Geophys Geosyst Q0AD22, doi:10.1029/2011GC003782

Kirschvink UL (1980) The least-squares line and plane and the analysis of palaeomagnetic data. Geophys J Int 62:699-718

Liu B, Saito Y, Yamazaki T, Abdeldayem A, Oda H, Hori K, Zhao O (2001) Paleocurrent analysis for the late Pleistocene-Holocene incised-valley fill of the Yangtze delta, China by using anisotropy of magnetic susceptibility. Mar Geol 176:175-189

Parés JM, van der Pluijm BA, Dinarés-Turell J (1999) Evolution of magnetic fabrics during incipient deformation of mud rock (Pyrenees, northern Spain). Tectonophysics 307:1-14

Parés JM, Hassold NJC, Rea DK (2007) Paleocurrent directions from paleomagnetic reorientation of magnetic fabrics in deep-sea sediments at the Antarctic Peninsula Pacific margin. Mar Geol 242:261-269

Rosenbaum J, Reynolds R, Smoot J, Meyer R (2000) Anisotropy of magnetic susceptibility as a tool for recognizing core deformation: reevaluation of the paleomagnetic record of Pleistocene sediments from drill hole OL-92, Owens Lake, California. Earth Planet Sci Lett 178:415-424

Skinner L, MCCave IN (2003) Analysis and modeling of gravity- and piston coring based on soil mechanics. Mar Geol 199:181-204. doi:10.1016/S0025-3227(3)00127-0

Széréméta N, Bassinot F, Balut Y, Labeyrie L (2004) Oversampling of sedimentary series collected by giant piston core: evidence and corrections based on 3.5-kHz chirp profiles. Paleoceanography 19:PA1005

Tarling DH, Hrouda F (1993) The magnetic anisotropy of rocks. Chapman and Hall, London, p 217 
Tauxe L (1998) Paleomagnetic principles and practice. Kluwer, Boston, p 299 Ujiie K, Hisamitsu T, Taira A (2003) Deformation and fluid pressure variation during initiation and evolution of the plate boundary decollement zone in the Nankai accretionary prism. J Geophys Res 108:2398, doi:10.1029/2002JB002314

Weaver PPE, Schultheiss PJ (1983) Detection of repenetration and sediment disturbance in open-barrel gravity cores. J Sed Petrol 53:649-678

Yamazaki T, Kanamatsu T (2007) A relative paleointensity record of the geomagnetic field since 1.6 Ma from the North Pacific. Earth Planets Space 59:785-794

Yamazaki T, Inoue S, Shimono T (2013) Sea-ice conditions in the Okhotsk Sea during the last $550 \mathrm{kyr}$ deduced from environmental magnetism. Geochem Geophys Geosyst 14: doi:10.1002/2013GC004959

doi:10.1186/1880-5981-66-3

Cite this article as: Shimono et al:: Influence of sampling on magnetic susceptibility anisotropy of soft sediments: comparison between gravity and piston cores. Earth, Planets and Space 2014 66:3.

\section{Submit your manuscript to a SpringerOpen ${ }^{\circ}$ journal and benefit from:}

- Convenient online submission

- Rigorous peer review

- Immediate publication on acceptance

- Open access: articles freely available online

- High visibility within the field

- Retaining the copyright to your article 